\title{
Multimodal monitoring combined with hypothermia for the management of severe traumatic brain injury: A case report
}

\author{
JUN-HUI CHEN $^{1 *}$, YI-NONG XU ${ }^{2 *}$, MENG JI $^{2 *}$, PEI-PEI LI ${ }^{1}$, LI-KUN YANG ${ }^{1}$ and YU-HAI WANG ${ }^{1}$ \\ ${ }^{1}$ Department of Neurosurgery, 101st Hospital of The People's Liberation Army, Wuxi, Jiangsu 214044; \\ ${ }^{2}$ Department of Neurosurgery, Taizhou No. 4 Hospital, Taizhou, Jiangsu 225300, P.R. China
}

Received August 21, 2017; Accepted February 2, 2018

DOI: $10.3892 /$ etm.2018.5994

\begin{abstract}
Traumatic brain injury (TBI) is a prominent public health issue that has a significant negative impact on patients and their family members. It is the leading cause of mortality and disability among young (below 50 years old) individuals. Intracranial hypertension (ICH) remains the single most difficult therapeutic challenge for the management of severe TBI. Therapeutic hypothermia may reduce intracranial hypertension and improve patient outcomes; however, the use of hypothermia is controversial. It has been reported that therapeutic hypothermia elicits no therapeutic benefit for patients with TBI. The present study presents two patients with severe(s) TBI who were admitted to 101st Hospital of the People's Liberation Army Between June 2017 to October 2017. Multimodal brain monitoring measurements of intracranial pressure, cerebral perfusion pressure (CPP) and bispectral index (BIS) were used during assisted hypothermia for management of patients with sTBI. The duration, degree of hypothermia treatment and speed of re-warming were assessed.
\end{abstract}

\section{Introduction}

Traumatic brain injury (TBI) has a high morbidity and has a significantly negative impact on the lives of patients and their families (1-4). The U.S. Centers for Disease Control and Prevention reported that the combined incidence of TBI-associated hospitalizations, emergency department visits and mortality was 823.7 per 100,000 in 2010 (5).

Correspondence to: Dr Yu-Hai Wang or Dr Li-Kun Yang, Department of Neurosurgery, 101st Hospital of The People's Liberation Army, 101 Xing Yuan North Road, Wuxi, Jiangsu 214044, P.R. China

E-mail:wangyuhai67@126.com

E-mail: beck_yang@163.com

*Contributed equally

Key words: multimodal monitoring, hypothermia, traumatic brain injury
Intracranial hypertension ( $\mathrm{ICH}$ ) is an important predictor of mortality in patients with severe TBI and patient outcomes and mortality can be improved if the ICH is well managed (6-8). In a meta-analysis, Sadaka and Veremakis (8) reported the effectiveness of mild-to-moderate therapeutic hypothermia in controlling ICH in patients with severe TBI. The use of therapeutic hypothermia as a neuroprotective strategy was first reported in the 1940s (9). A number of studies have demonstrated that therapeutic hypothermia is useful for improving patient outcomes and reducing mortality (10-12). Furthermore, recently published randomized trials reported that hypothermia had no therapeutic benefit in terms of mortality or morbidity (13-15). Variation between studies, including in the duration and degree of hypothermia, may impact their clinical efficacy.

Multimodal brain monitoring is an important tool that may provide key information to guide the management of severe TBI in adults $(16,17)$. A number of studies have reported the use of non-invasive multimodal brain monitoring of continuous electroencephalography and the bispectral index (BIS) in the treatment of patients with severe TBI (sTBI) patients; these parameters may allow for the development of patient-tailored treatments and help to determine when the brain is at risk of injury and the depth of sedation required (18-20).

The present study presents two patients with sTBI who were admitted to the Center for Craniocerebral Injuries of the 101st Hospital of the People's Liberation Army (Wuxi, China). Additionally, the present study mainly focused on the value of multimodal monitoring combined with the effectiveness of hypothermia management of sTBI.

\section{Case report}

Case one. A 17-year-old female was found unconscious on the stairs at her school in October 2016. The exact mechanism of injury was unclear. The patient was brought to the emergency department of the 101st Hospital of the People's Liberation Army by ambulance within 15 min of being found. Upon arrival of the patient, an arterial line and central venous catheters were inserted for fluid and medication administration and her vital signs, ultrasonography and electroencephalography (EEG) were monitored. Emergency treatment comprised endotracheal intubation to improve hypoxia and administration of mannitol $(250 \mathrm{ml}, 20 \%)$ and hypertonic 
saline $(100 \mathrm{ml}, 7.5 \%)$ to improve cerebral hernia. The patient was examined and a Glasgow Coma Scale (GCS) score of 4 was determined, as well as $4.0 \mathrm{~mm}$ bilaterally fixed pupils and a negative corneal response. A cranial computed tomography (CT) scan revealed subarachnoid hemorrhage, left occipital bone fracture, right subdural hematoma, compressed cisterns and a notable midline shift (Fig. 1A). The patient was prepared for surgery and an intracranial pressure (ICP) probe was implanted.

The ICP prior to surgery was recorded as $47 \mathrm{mmHg}$. The patient underwent a craniotomy and right-sided decompressive craniotomy. The hematoma was removed and the ICP decreased to $5 \mathrm{mmHg}$; however, intraoperative ICP monitoring revealed that the ICP progressively increased to $18 \mathrm{mmHg}$ within $1 \mathrm{~h}$. Intraoperative ultrasound and intraoperative CT scan confirmed an occipital epidural hematoma (Fig. 1B). The original incision was extended to remove the epidural hematoma and the ICP returned to $5 \mathrm{mmHg}$. The patient was subsequently transferred to the neurointensive care unit (NICU) where she underwent a postoperative examination and received continuous BIS, ICP, CPP and ultrasound monitoring under the care of a neurosurgeon and an intensivist. The patient's GCS post-surgery was 5 and the bilateral pupils were $4.0 \mathrm{~mm}$ with a negative corneal response. A subsequent cranial CT scan revealed an improvement of the midline shift (Fig. 1C).

During the first $24 \mathrm{~h}$ following admission, the primary aim was of treatment was to improve the internal environment and address any coagulation disorders. Following a $24 \mathrm{~h}$ admission, the CPP and ICP were normal (65-80 and 15-20 $\mathrm{mmHg}$, respectively). The patient's BIS was 55-65 and ultrasound revealed a pulsatility index $(\mathrm{PI}) \sim 1.35$.

On the second day following admission, the patient's ICP increased to $25 \mathrm{mmHg}$, CPP decreased to $55-70 \mathrm{mmHg}$ and PI increased to 1.6. The patient received analgesia (Fentanyl Citrate, $0.001 \mathrm{mg} / \mathrm{kg}$ per $4 \mathrm{~h}$ ), sedation (Dexmedetomidine, $0.1 \mu \mathrm{g} / \mathrm{kg}$ per hour) and hypertonic salt $(4.5 \% \mathrm{NaCl})$ treatment Following $6 \mathrm{~h}$ of treatment, the ICP decreased to $17 \mathrm{mmHg}$.

On the third day, the patient's ICP increased to $35 \mathrm{mmHg}$ and the she presented a higher PI (2.3) and lower CPP (45-65 mmHg). CT scans revealed brain swelling (Fig. 1D). At this point, hypothermia was implemented to control the ICP until coagulation patterns returned to normal. The specific treatment parameters were as follows: Temperature, $36^{\circ} \mathrm{C}$; target $\mathrm{ICP}, \sim 20 \mathrm{mmHg}$; target $\mathrm{CPP}, \sim 70 \mathrm{mmHg}$.

During the fourth day, ICP, CPP and PI were poorly controlled; the patient's temperature was decreased to $35^{\circ} \mathrm{C}$ and she was deeply sedated with a lower BIS (40-50) and placed on a ventilator. The ICP, PI and CPP subsequently returned to normal levels and were within acceptable ranges. The patient was subjected to hypothermic treatment for a total of 10 days (Fig. 1E).

At 23 days post-injury, the patient had complete resolution of disease with mild language disorders and a GCS score of 4 . A cranial CT scan revealed that the edema and hematoma were no longer present (Fig. 1F).

In this case, multimodal brain monitoring was used to provide important information and insight about the patient's condition, allowing for precise treatment of TBI. Intraoperative ultrasound may contribute to a quick diagnosis and better surgical planning. ICP, CPP, BIS and PI monitoring may provide additional information and support during the initiation and management of hypothermia, minimizing complications and maximizing the efficacy of treatment.

Case two. A 55-year-old male was rendered unconscious following a fall from a great height $(8 \mathrm{~m})$ at his place of work. The patient was admitted to the emergency department at a Level 2 hospital (Huishan People's hospital, Wuxi, China) via ambulance in May 2016, within 30 min of injury. Physical examination revealed a GCS of 6 and $3 \mathrm{~mm}$ bilateral pupils with a normal light reflex. A cranial CT scan revealed subarachnoid hemorrhage, bilateral subdural hemorrhage and severe cranial comminuted fractures (Fig. 2A). The patient's initial ICP was $27 \mathrm{mmHg}$ and he underwent a craniotomy to remove the hematoma and brain contusion. This patient did not receive decompressive craniectomy (DC) as ICP levels were $5 \mathrm{mmHg}$ following surgery. The patient was subsequently sent to the NICU and postoperatively examined by a neurosurgeon, who reported a GCS of 7 and bilateral pupils at $3.0 \mathrm{~mm}$ with a positive corneal response. A cranial CT scan revealed improvement of the midline shift and complete removal of the brain contusion (Fig. 2B); however, the patient developed a high fever and blood coagulation disorders on the second day post-surgery and his ICP levels progressively increased to $28 \mathrm{mmHg}$. Due to the development of blood coagulation disorders and the patient's family not consenting to a second operation or DC.

On the third day post-surgery, the patient's ICP levels were $>37 \mathrm{mmHg}$ and he was referred to the NICU at the 101st Hospital of the People's Liberation Army. When the patient arrived at the NICU multimodal monitoring was conducted as described in case 1 and the patient underwent an additional CT examination. A cranial CT scan revealed brain swelling, cerebral ischemia and re-bleeding (Fig. 2C). The ICP levels increased to $56 \mathrm{mmHg}$ with a higher PI (3.4) and lower CPP $(40-55 \mathrm{mmHg})$. At this point, hypothermia was implemented to control the ICP. The specific treatment parameters were as follows: Temperature, $34.5^{\circ} \mathrm{C}$; target ICP, $\sim 28 \mathrm{mmHg}$; target $\mathrm{CPP}, \sim 65 \mathrm{mmHg}$. However, no improvements were observed 1 day following the initiation of hypothermia and the patient presented with an ICP of $\sim 33 \mathrm{mmHg}$. The patient was deeply sedated (general anesthesia, (Fentanyl Citrate, $0.001 \mathrm{mg} / \mathrm{kg}$ per $4 \mathrm{~h}$ ), sedation (Dexmedetomidine, $0.1 \mu \mathrm{g} / \mathrm{kg}$ per hour), BIS $\sim 45$, no breathing- and respirator-assisted respiration). Subsequently, the ICP remained stable, $>30 \mathrm{mmHg}$ and the PI was $<1.8$. The duration of hypothermia treatment was 15 days (Fig. 2D).

At 30 days post-injury, the patient was discharged to a rehabilitation hospital (Huishan People's hospital, Wuxi, China) with a GCS of 10. Cranial CT re-examination revealed decreased cerebral ischemia and complete absorption of brain edema and hematoma (Fig. 2E).

In this case, ICP, CPP and PI were very important indices of TBI, which were the target of the hypothermia treatment conducted in the present study. ICP can be controlled by regulating the degree of hypothermia and the dose of dehydrant (mannitol, Beijing Double-Crane Pharmaceutical Co., Ltd., Beijing, China). BIS monitoring may reflect the depth of coma and sedation; additionally, the depth of sedation may 

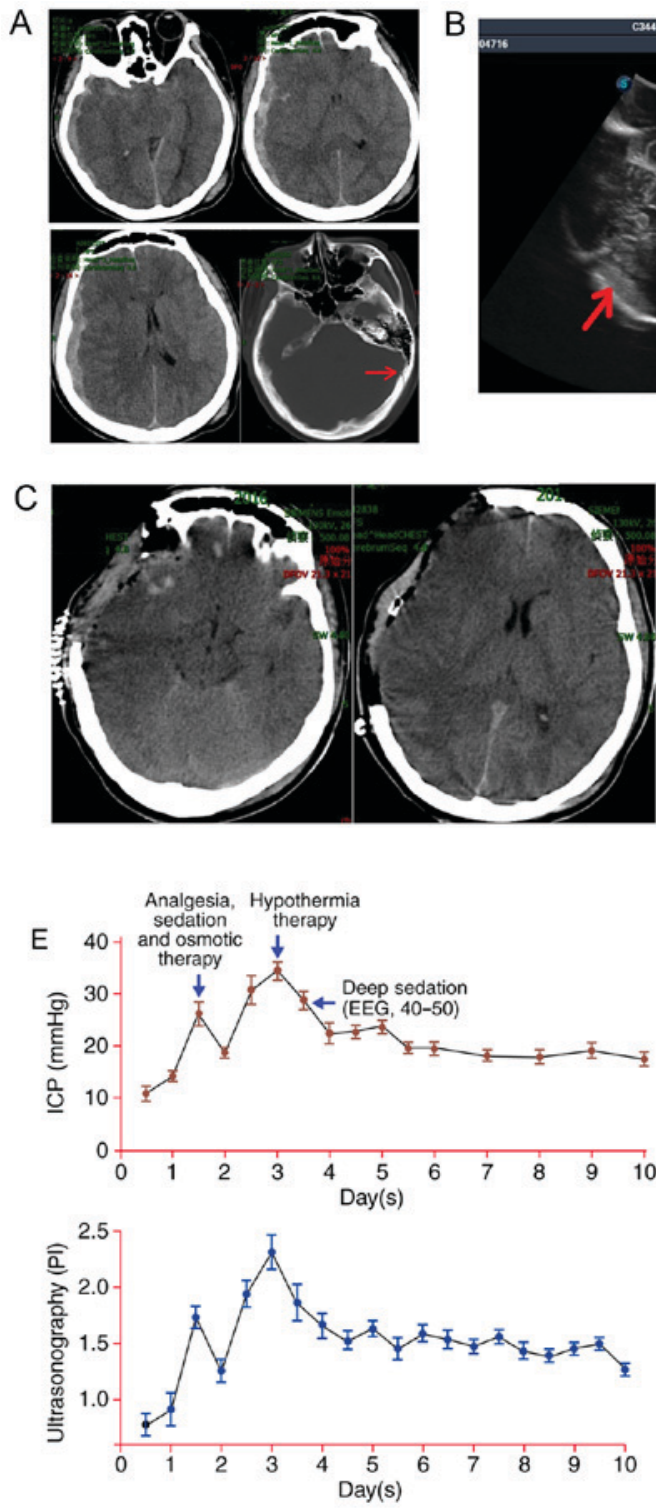
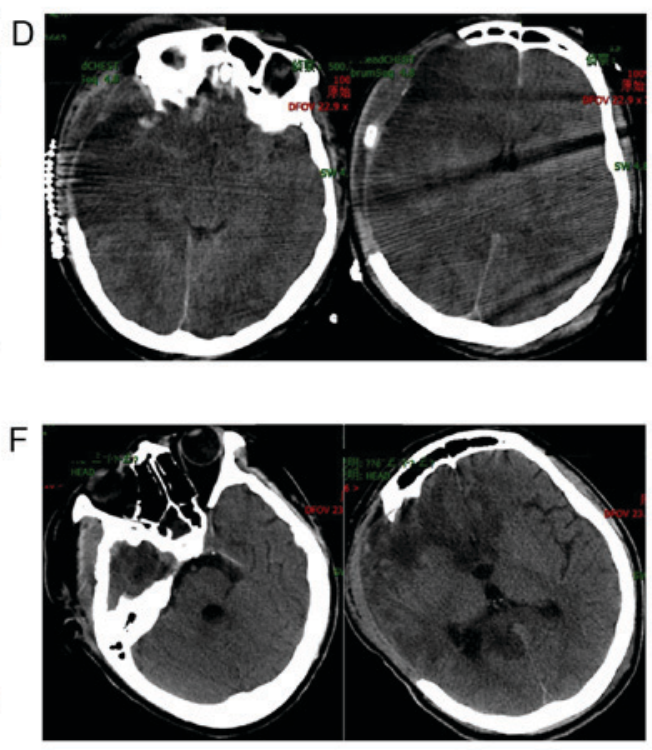

Figure 1. A 17-year-old girl presented with a head injury of unknown origin. (A) Cranial CT revealed subarachnoid hemorrhage, left occipital bone fracture (red arrow), right subdural hematoma, compressed cisterns and obvious midline shift. (B) Intraoperative ultrasound and intraoperative cranial CT revealed occipital epidural hematoma (red arrow). (C) Postoperative CT was used to confirm removal of the hematoma and improvement of the midline shift. (D) On day 3 post-surgery, cranial CT revealed brain swelling and compressed cisterns. (E) ICP and PI over a 10-day period. (F) At 23 days post-surgery, a cranial CT scan revealed complete absorption of the edema and hematoma. CT, computed tomography; ICP, intracranial pressure; PI, pulsatility index; EEG, electroencephalography.

be regulated to control ICP and reduce hypothermia-relevant complications.

\section{Discussion}

TBI is one of the most common ailments worldwide, with high morbidity and mortality, (6). Elevated ICP is an important predictor of mortality in patients with STBI and controlling the ICP has been demonstrated to reduce mortality and improve patient outcome $(6,21)$. However, methods used to control ICP require further investigation; DC and osmotic therapy are appropriate options (22); however, these treatments offer no significant curative effect following the administration of analgesia, sedation and osmotic therapy (22). Hypothermia is an alternative treatment that is able to effectively control ICP levels $(8,10-12,23,24)$. Schreckinger and Marion (23) indicated that therapeutic moderate hypothermia was as effective or more effective than other treatments for ICH. Furthermore, there is no evidence of clinical complications associated with therapeutic hypothermia. Previous studies have stated that hypothermia does not confer a therapeutic benefit to mortality or morbidity $(13-15,25,26)$. However, previous negative findings may be a result of inappropriate implementation of hypothermia, including the wrong duration and degree of treatment. Precise monitoring is necessary to evaluate the degree and duration of therapeutic hypothermia. Therefore, multimodal monitoring is an important tool that may provide support for patients who undergo hypothermia treatment. Both patients described in the present study received long-term mild to moderate hypothermia treatment and multimodal monitoring and ICP was successfully controlled. 

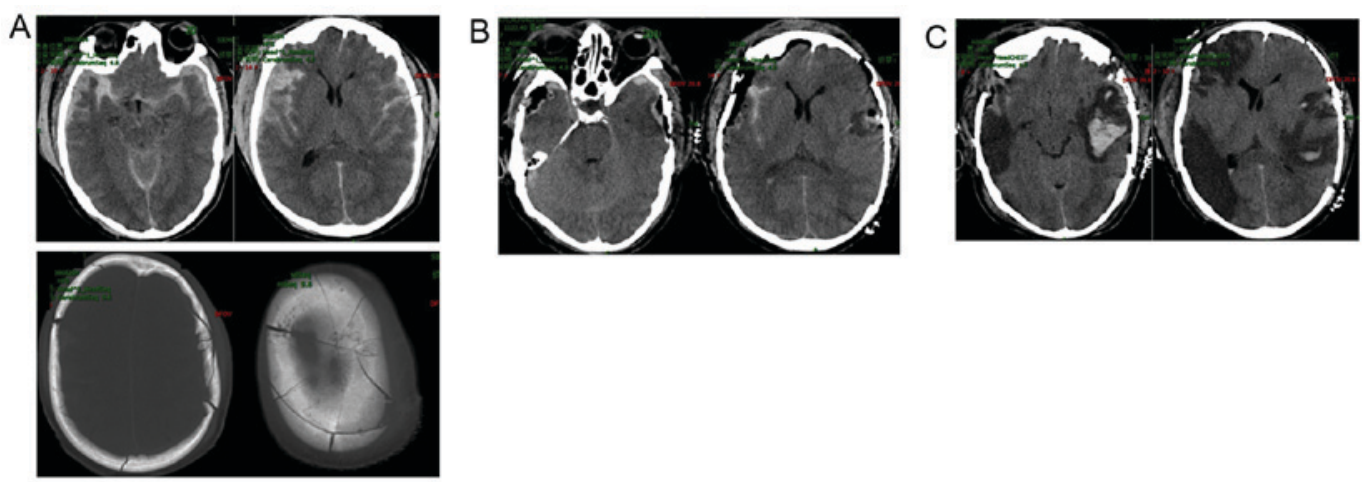

D

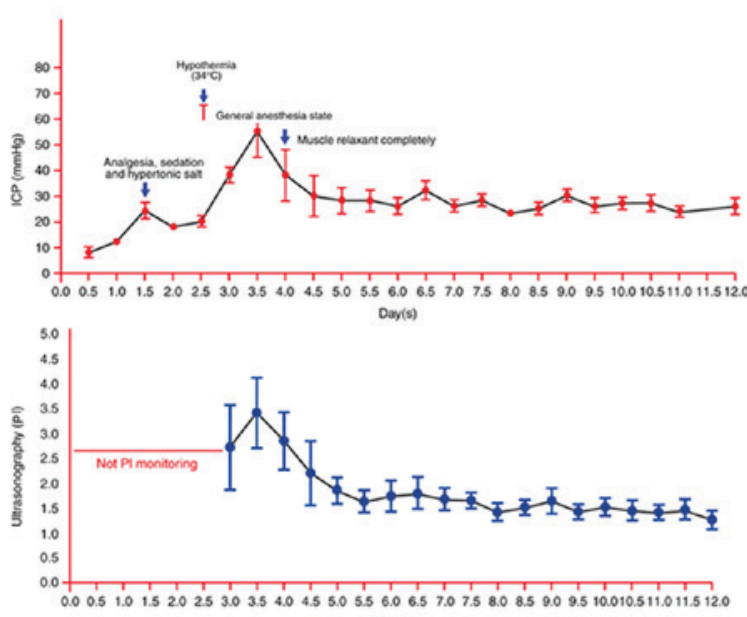

$\mathrm{E}$

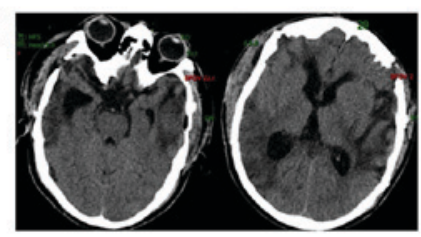

Figure 2. A 55-year-old man presented with head trauma following a workplace fall. (A) Cranial CT revealed subarachnoid hemorrhage, bilateral subdural hemorrhage and severe comminuted cranial fractures. (B) Postoperative cranial CT revealed improvement of the midline shift and removal of the brain contusion. (C) On day 1 post-surgery, cranial CT revealed brain swelling, cerebral ischemia and re-bleeding. (D) ICP and PI monitoring for 12 days. (E) At 30 days post-surgery, cranial CT revealed decreased cerebral ischemia and complete absorption of brain edema and hematoma. CT, computed tomography; ICP, intracranial pressure; PI, pulsatility index.

The majority of multimodal brain monitoring methods are rapid and non-invasive and no particular contraindications are usually observed. Implantation of the ICP probe is an invasive operation that required minor injury; a small proportion of patients with blood coagulation disorders, old age or unstable vital signs may be unsuitable for ICP-monitored surgery (22). Therefore, multimodal brain monitoring may be highly applicable to the general population.

Multimodal brain monitoring is an important tool used for the rapid diagnosis of TBI. Ultrasound may provide a quick assessment of intracranial condition. In addition, BIS and PI may also aid in the determination of disease severity; however, CT scans are important for the analysis of TBI and cannot be replaced with other techniques. Additionally, multimodal brain monitoring has previously been employed to guide the management of sTBI. It is able to provide clinicians with an early indication of potential secondary complications in the recovering brain by identifying diagnostic features, including elevated ICP and decreased CPP (17) but may also aid the management of the target temperature and ICP. EEG and BIS serve important roles in the treatment of critically ill patients, particularly those suffering from sTBI and can improve their clinical outcome $(19,27-30)$. Therefore, monitoring a barbiturate-induced coma using BIS is an interesting approach as it can provide a continuous suppression ratio and raw EEG traces, which enable monitoring of cerebral function (19). Bader et al (30) reported that the EEG-based technology in BIS monitors may be an additional tool that can be used in the ICU. The goal of BIS monitoring in STBI is to reduce ICP and secondary injury, thereby improving patient outcome. BIS scores may reflect the depth of coma and sedation, which may then be regulated to control ICP. In the cases described in the present study, both patients underwent BIS monitoring to regulate the depth of sedation and control ICP; consequently, both patients had good treatment outcomes.

Ultrasonography is easy to use, noninvasive and is frequently used during early injury assessment, as well during the assessment of patients with sTBI and elevated ICP. Transcranial Doppler (TCD) ultrasonography is typically used to determine the PI of TCD waveforms (31). A significant correlation between CPP, ICP and PI has been reported $(32,33)$ and Tan et al (32) suggested that TCD ultrasonography may be used to predict patient outcome at 6 months post-injury. Mayans et al (34) reported that serial TCD monitoring may allow for potentially fatal complications to be identified in time to allow a life-saving intervention in the ICU setting. A number of studies have reported that TCD ultrasonography is of great clinical value for measuring PI in the management of sTBI $(34,35)$. Furthermore, it has been reported that PI correlates well with the ICP as 
measured using invasive methods (36). Amyot et al (31) summarized the role of TCD for the evaluation of ICH as follows: i) TCD waveform alterations indicate an abnormally high ICP, particularly 20 to $30 \mathrm{mmHg}$; ii) TCD alterations may indicate that the ICP probe is malfunctioning and alert NICU personnel; iii) abnormally and globally decreased patterns of CBFVs with increased PIs indicate the onset of diffuse intracranial hypertension; and iv) the sudden onset of asymmetrical CBFVs and PI alterations may indicate a potential midline shift. At present, ultrasonography is not a viable replacement for ICP as ICP monitoring is more accurate and may be performed continuously and in real time. Further randomized controlled trials studies are required to evaluate the ultrasonography as a potential substitute for ICP monitoring in STBI.

The cases presented herein demonstrate that hypothermia is a highly useful tool for controlling malignant ICH in sTBI. The present study provides further evidence that multimodal monitoring is useful in the management and optimization of therapeutic hypothermia. Additionally, long-term mild hypothermia may improve sTBI patient outcomes. The ICP, PI and EEG appear to be associated with patient outcomes and may be used to guide treatment for TBI in the NICU. A large multicenter, prospective study is required to validate these results.

\section{Acknowledgements}

Not applicable.

\section{Funding}

No funding was received.

\section{Availability of data and methods}

The analyzed data sets generated during the present study are available from the corresponding author on reasonable request.

\section{Authors' contributions}

LKY made substantial contributions to the design of the study. YHW made substantial contributions to the conception and design of the study. JHC made substantial contributions to the conception and design of the study, as well as the acquisition, analysis and interpretation of data. YNX made substantial contributions to the conception and design of the study, as well as the acquisition of data. PPL gave final approval of the version to be published and made substantial contributions to the conception and design of the study. JHC, YNX and PPL contributed in drafting the manuscript and revising it critically for important intellectual content. MJ contributed in drafting the manuscript and revising it critically for important intellectual content, as well as the collection of data.

\section{Ethics approval and consent to participate}

The present study was approved by the Medical Ethics Committee of the 101st Hospital of the People's Liberation Army. Written informed consent was obtained from all participants.

\section{Consent for publication}

All patients provided consent for publication.

\section{Competing interests}

The authors declare that they have no competing interests.

\section{References}

1. Roozenbeek B, Maas AI and Menon DK: Changing patterns in the epidemiology of traumatic brain injury. Nat Rev Neurol 9: 231-236, 2013

2. Corrigan JD, Selassie AW and Orman JA: The epidemiology of traumatic brain injury. J Head Trauma Rehabil 25: 72-80, 2010.

3. Selassie AW, Zaloshnja E, Langlois JA, Miller T, Jones P and Steiner C: Incidence of long-term disability following traumatic brain injury hospitalization, United States, 2003. J Head Trauma Rehabil 23: 123-131, 2008.

4. Abbasi HR, Mousavi SM, Taheri Akerdi A, Niakan MH, Bolandparvaz S and Paydar S: Pattern of traumatic injuries and injury severity score in a major trauma center in Shiraz, Southern Iran. Bull Emerg Trauma 1: 81-85, 2013.

5. Centers for Disease Control and Prevention: Rates of TBI-related emergency department visits, hospitalizations and deaths-United States, 2001-2010. http://www.cdc.gov/traumaticbraininjury/data/rates.html. Accessed August 10, 2015.

6. Patel HC, Menon DK, Tebbs S, Hawker R, Hutchinson PJ and Kirkpatrick PJ: Specialist neurocritical care and outcome from head injury. Intensive Care Med 28: 547-553, 2002.

7. Juul N, Morris GF, Marshall SB and Marshall LF: Intracranial hypertension and cerebral perfusion pressure: Influence on neurological deterioration and outcome in severe head injury. The executive committee of the international selfotel trial. J Neurosurg 92: 1-6, 2000.

8. Sadaka F and Veremakis C: Therapeutic hypothermia for the management of intracranial hypertension in severe traumatic brain injury: A systematic review. Brain Inj 26: 899-908, 2012.

9. Fay T: Observations on prolonged human refrigeration. NY State J Med 40: 1351-1354, 1940.

10. Clifton GL, Miller ER, Choi SC, Levin HS, McCauley S, Smith KR Jr, Muizelaar JP, Wagner FC Jr, Marion DW, Luerssen TG, et al: Lack of effect of induction of hypothermia after acute brain injury. N Engl J Med 344: 556-563, 2001.

11. Zhi D, Zhang S and Lin X: Study on therapeutic mechanism and clinical effect of mild hypothermia in patients with severe head injury. Surg Neurol 59: 381-385, 2003.

12. Qiu W, Zhang Y, Sheng H, Zhang J, Wang W, Liu W, Chen K, Zhou J and Xu Z: Effects of therapeutic mild hypothermia on patients with severe traumatic brain injury after craniotomy. J Crit Care 22: 229-235, 2007.

13. Nielsen N, Wetterslev J, Cronberg T, Erlinge D, Gasche Y, Hassager C, Horn J, Hovdenes J, Kjaergaard J, Kuiper M, et al: Targeted temperature management at $33^{\circ} \mathrm{C}$ vs. $36^{\circ} \mathrm{C}$ after cardiac arrest. N Engl J Med 369: 2197-2206, 2013.

14. Hutchison JS, Ward RE, Lacroix J, Hébert PC, Barnes MA, Bohn DJ, Dirks PB, Doucette S, Fergusson D, Gottesman R, et al: Hypothermia therapy after traumatic brain injury in children. N Engl J Med 358: 2447-2456, 2008.

15. Clifton GL, Valadka A, Zygun D, Coffey CS, Drever P, Fourwinds S, Janis LS, Wilde E, Taylor P, Harshman K, et al: Very early hypothermia induction in patients with severe brain injury (the National Acute Brain Injury Study: Hypothermia II): A randomised trial. Lancet Neurol 10: 131-139, 2011.

16. Le Roux P, Menon DK, Citerio G, Vespa P, Bader MK, Brophy G, Diringer MN, Stocchetti N, Videtta W, Armonda R, et al: The international multidisciplinary consensus conference on multimodality monitoring in neurocritical care: Evidentiary tables: A statement for healthcare professionals from the neurocritical care society and the european society of intensive care medicine. Neurocrit Care 21 (Suppl 2): S282, 2014.

17. Young AM, Donnelly J, Czosnyka M, Jalloh I, Liu X, Aries MJ, Fernandes HM, Garnett MR, Smielewski P, Hutchinson PJ and Agrawal S: Continuous multimodality monitoring in children after traumatic brain injury-preliminary experience. PLoS One 11: e0148817, 2016. 
18. Irimia A, Goh SY, Torgerson CM, Stein NR, Chambers MC, Vespa PM and Van Horn JD: Electroencephalographic inverse localization of brain activity in acute traumatic brain injury as a guide to surgery, monitoring and treatment. Clin Neurol Neurosurg 115: 2159-2165, 2013.

19. Prins SA, de Hoog M, Blok JH, Tibboel D and Visser GH: Continuous noninvasive monitoring of barbiturate coma in critically ill children using the Bispectral index monitor. Crit Care 11: R108, 2007.

20. Steinbaugh LA, Lindsell CJ, Shutter LA and Szaflarski JP: Initial EEG predicts outcomes in a trial of levetiracetam vs. fosphenytoin for seizure prevention. Epilepsy Behav 23: 280-284, 2012

21. Steiner T, Ringleb P and Hacke W: Treatment options for large hemispheric stroke. Neurology 57(5 Suppl 2): S61-S68, 2001.

22. Carney N, Totten AM, O'Reilly C, Ullman JS, Hawryluk GW, Bell MJ, Bratton SL, Chesnut R, Harris OA, Kissoon N, et al: Guidelines for the management of severe traumatic brain injury, 4th Edition. Neurosurgery 80: 6-15, 2017.

23. Schreckinger M and Marion DW: Marion. Contemporary management of traumatic intracranial hypertension: Is there a role for therapeutic hypothermia? Neurocrit Care 11: 427-436, 2009.

24. Corry JJ: The use of targeted temperature management for elevated intracranial pressure. Curr Neurol Neurosci Rep 14 453, 2014.

25. Raj R, Bendel S, Reinikainen M, Kivisaari R, Siironen J, Lång M and Skrifvars M: Hyperoxemia and long-term outcome after traumatic brain injury. Crit Care 17: R177, 2013.

26. Kilgannon JH, Jones AE, Shapiro NI, Angelos MG, Milcarek B, Hunter K,Parrillo JE and Trzeciak S: Emergency Medicine Shock Research Network (EMShockNet) Investigators: Association between arterial hyperoxia following resuscitation from cardiac arrest and in-hospital mortality. JAMA 303: 2165-2171, 2010.

27. Lafrance WC Jr, Deluca M, Machan JT and Fava JL: Traumatic brain injury and psychogenic nonepileptic seizures yield worse outcomes. Epilepsia 54: 718-725, 2013.

28. Vespa PM, McArthur DL, Xu Y, Eliseo M, Etchepare M, Dinov I, Alger J, Glenn TP and Hovda D: Nonconvulsive seizures after traumatic brain injury are associated with hippocampal atrophy. Neurology 75: 792-798, 2010.
29. Cottenceau V, Petit L, Masson F, Guehl D, Asselineau J, Cochard JF, Pinaquy C, Leger A and Sztark F: The use of bispectral index to monitor barbiturate coma in severely brain-injured patients with refractory intracranial hypertension. Anesth Analg 107: 1676-1682, 2008.

30. Bader MK, Arbour R and Palmer S: Refractory increased intracranial pressure in severe traumatic brain injury, barbiturate coma and bispectral index monitoring. AACN Clin Issue 16: 526-541, 2005.

31. Amyot F, Arciniegas DB, Brazaitis MP, Curley KC, Diaz-Arrastia R, Gandjbakhche A, Herscovitch P, Hinds SR II, Manley GT, Pacifico A, et al: A Review of the effectiveness of neuroimaging modalities for the detection of traumatic brain injury. J Neurotrauma 32: 1693-1721, 2015.

32. Tan H, Feng H, Gao L, Huang G and Liao X: Outcome prediction in severe traumatic brain injury with transcranial Doppler ultrasonography. Chin J Traumatol 4: 156-160, 2001.

33. Zweifel C, Czosnyka M, Carrera E, de Riva N, Pickard JD and Smielewski P: Reliability of the blood flow velocity pulsatility index for assessment of intracranial and cerebral perfusion pressures in head-injured patients. Neurosurgery 71: 853-861, 2012.

34. Mayans DR, Meads DB and Reynolds PS: Transcranial doppler identifies a malfunctioning extraventricular drain. J Neuroimaging 24: 518-519, 2013.

35. Daboussi A, Minville V, Leclerc-Foucras S, Geeraerts T, Esquerre JP, Payoux P and Fourcade O: Cerebral hemodynamic changes in severe head injury patients undergoing decompressive craniectomy. J Neurosurg Anesthesiol 21: 339-345, 2009.

36. Moppett IK and Mahajan RP: Transcranial Doppler ultrasonography in anaesthesia and intensive care. Br J Anaesth 93: 710-724, 2004.

This work is licensed under a Creative Commons Attribution-NonCommercial-NoDerivatives 4.0 International (CC BY-NC-ND 4.0) License. 